\title{
Editorial
}

\section{Therapy for Locally Advanced Heptocellular Carcinoma, Role of Anti- Angiogenesis.}

\author{
Mahmoud Abdelsalam \\ Professor of Clinical Oncology, NEMROCK, Cairo University.
}

Treatment options for hepatocellular carcinoma (HCC) depend on the stage of the disease and the extent of liver dysfunction and cirrhosis. The Barcelona Clinic Liver Cancer staging system provides an algorithm that describes therapeutic options available for each stage of the disease (Figure 1). Several controversies surround the treatment strategies; these issues will be addressed, along with the addition of sorafenib to the armamentarium of therapies for locally advanced $\mathrm{HCC}^{1}$.

The dual blood supply of the liver drives the development of many local therapies that selectively target hepatocellular carcinoma (HCC) lesions overperfused by the hepatic artery instead of the background liver parenchyma perfused through the portal venous system. Transarterial chemoembolization (TACE) is considered an acceptable standard of care for the treatment of locally advanced HCC that is not amenable to surgical resection or transplantation. This is based on the results of 2 clinical trials that have shown a survival advantage for TACE over symptomatic treatment. In 1 clinical trial of 112 patients with unresectable HCC, patients were randomized to either bland arterial embolization (ie, no chemotherapy), TACE using doxorubicin, or best supportive care. Treatment with TACE resulted in a survival advantage compared with conservative treatment (1-year survival: $82 \%$ vs $63 \%$; 2-year survival: $63 \%$ vs $27 \% ; P=.009)^{2}$. Of note, no clinical trial has demonstrated a difference in survival between patients treated with bland arterial embolization and those treated TACE. A second study randomizing patients to TACE using cisplatin vs symptomatic management has shown a similar survival advantage in favor of TACE (1-year survival: $57 \%$ vs $32 \%$; 2 -year survival: $31 \%$ vs $11 \%$; 3 -year survival: $26 \%$ vs $3 \% ; P=.002)^{3}$. However, these positive outcomes were not reproduced in other trials ${ }^{4-6}$. A meta-analysis including 2466 patients from randomized controlled trials conducted between 1980 and 2000 concluded that TACE significantly reduces overall 2-year mortality ${ }^{7}$. TACE, however, was not found to be more effective than bland arterial embolization. Two other recent meta-analyses reported no survival advantage for various local therapies, including $\mathrm{TACE}^{8,9}$. A trial is currently underway comparing response in patients treated with bland arterial embolization (ie, using beads alone) vs TACE using doxorubicin-eluting beads ${ }^{10}$. Until the results from this trial are reported, both TACE and bland arterial embolization remain accepted approaches for patients with regionally confined unresectable HCC.

Another local mode of therapy that is gaining popularity is radioembolization using intrahepatic arterial administration of yttrium 90 (Y90)-tagged glass (TheraSphere) or resin (SIR-Spheres) microspheres. Because HCC is a hypervascular tumor, micropsheres injected intraarterially will preferentially deliver to the tumor-bearing area and selectively emit high energy, high-penetrating-power radiation to the tumor. One of the advantages of radioembolization is that it can be used safely in patients with portal vein thrombosis, because it is less embolic and spares the arterial blood flow to the treated liver parenchyma. While multiple trials show that radioembolization has some antitumor activity, there are no prospective data showing improved survival benefits compared with placebo or TACE ${ }^{10,11}$.

There is a good rationale for using sorafenib in conjunction with local therapy such as transarterial chemoembolization (TACE) or radioembolization.

A study from China showed that TACE before hepatic resection enhances angiogenesis in HCC cells by upregulating the expression of vascular endothelial growth factor (VEGF) ${ }^{12}$. Importantly, however, it has been shown that after the TACE procedure there is a rise in serum VEGF levels, which can feed the residual cancerous tissue and allow tumor cell proliferation (Figure 2) ${ }^{13}$. Because of this, it might be beneficial to add an antiangiogenic agent to repress tumor angiogenesis after the patient has received therapies to induce tissue ischemia, such as TACE. Another potential advantage of these combinations is that use of an antiangiogenic systemic agent might enable control of systemic tumor cell spread. In the SHARP study, about $50 \%$ of patients did receive some form of local therapy prior to treatment with sorafenib ${ }^{1}$.

Similar to combining sorafenib with surgical approaches in clinical trials of adjuvant therapy, one 
study evaluating combination therapy with TACE and sorafenib is already reported and others are under way. Table 1 provides currently available information about the combination of sorafenib with local therapy. As one can see, most of the trials are small retrospective or prospective studies in only abstract forms, with the exception of one phase III trial. In a randomized phase III trial, 458 patients from Japan and Korea treated with 1 or 2 TACE were randomized to receive either sorafenib or placebo ${ }^{14}$. The primary endpoint of time to progression based on independent review was not met: 5.4 months in the sorafenib group compared with 3.7 months in the placebo group (hazard ratio: $0.87 ; 95 \%$ confidence interval: $0.70-1.09 ; P=.25)$. This was interpreted as potentially due to greater rate of discontinuations and/ or the shorter duration of treatment in the sorafenib arm. Another explanation may be the delay of several weeks between the TACE procedure and the start of systemic therapy, as the angiogenic drive that is induced by TACE and is the target of sorafenib occurs at a minimum of 1 day after the procedure ${ }^{15}$; this window of efficacy may have been missed in this trial. It is hoped that this question will be addressed by an ongoing phase III study randomizing patients to TACE plus sorafenib vs placebo, where sorafenib or placebo are started before and continued throughout the TACE therapy ${ }^{16}$.

In conclusion, trials evaluating local therapy with and without sorafenib are very small and too premature. Most have been communicated only in the form of study abstracts, leaving many questions unanswered. Primary endpoints and response criteria were not well defined in most of these studies. Because of these factors, no robust conclusion can be drawn in regard to the combined therapies investigated thus far. The critical question that needs to be answered is whether the addition of sorafenib to local therapy induces a better outcome than local therapy alone. Okita et al. attempted to answer this question in a phase III trial ${ }^{14}$, but failed to do so because of several limitations.

There are other lingering questions as well. For example, when should we initiate treatment with sorafenib? Maybe it makes sense to start sorafenib prior to TACE in order to block upregulation of VEGF in the tumor as well as in serum. Should we stop sorafenib 1 to 2 days prior to initiating local therapy, given the concerns about toxicity? As one can see in (Table 1), the schedule of sorafenib administration is different in each trial. Another major problem is the lack of consistency regarding the frequency of scheduling TACE procedures and the type of chemotherapy agent or embolic material used. In the past, TACE has been given as frequently as two courses per month, but under this schedule it has induced hepatic decompensation in $7.5 \%$ of patients ${ }^{6,17}$. Clearly, the toxicity profile needs to be closely looked at with these combinations. Large phase II and III studies underway are using a combination of local therapy plus sorafenib; the outcomes of these trials are eagerly awaited. It is hoped that, as these data become more mature and as these studies are developed into full manuscripts, we will have better insights into these trials. In oncology, we have learned from the past that one plus one does not always equal two, and sometimes can equal zero. Therefore, careful consideration must be given prior to combining sorafenib with local therapy in patients with HCC.

Table 1: Outcome of Sorafenib in conjunction with local therapy.

\begin{tabular}{|c|c|c|c|c|c|}
\hline Study & Number & Treatment & Timing of Study (weeks) & Med. TTP (Months) & $\begin{array}{l}\text { Med. OS } \\
\text { (Months) }\end{array}$ \\
\hline Sinakos et al. ${ }^{18}$ & 14 & TACE +Sorafenib & 18 & NR & NR \\
\hline Duan et al. ${ }^{19}$ & 30 & TACE +Sorafenib & $3-4$ & NR & NR \\
\hline Cabrera et al. ${ }^{20}$ & 16 & Sorafenib alone or + TACE & NR & NR & NR \\
\hline Okita et al. ${ }^{16,21}$ & 458 & $\begin{array}{l}\text { TACE +Sorafenib (229) Vs. } \\
\text { TACE + Placebo(229) }\end{array}$ & $4-12$ & 5.4 vs. 3.7 & NR \\
\hline Martin et al..$^{21}$ & 30 & DEB-TACE +/-Sorafenib & NR & NR & 12 \\
\hline Reyes et al..$^{22}$ & 50 & DEB-TACE +Sorafenib & 1 week prior & NR & NR \\
\hline Chow ${ }^{23}$ & 35 & SIR-Sphero + Sorafenib & After LRT* & NR & 11.7 \\
\hline Chung et al. ${ }^{24}$ & 63 & TACE +Sorafenib & Cont.** & NR & NR \\
\hline \multicolumn{6}{|c|}{$\begin{array}{l}\text { LRT = Living Related Transplant. } \\
* * \text { Cont. = Continued sorafenib with dose interruption } 4 \text { days before and after TACE. } \\
\text { TTP = Time To Progression, OS = Overall Survival. }\end{array}$} \\
\hline
\end{tabular}




\section{BCLC staging and treatment strategy, 2008}

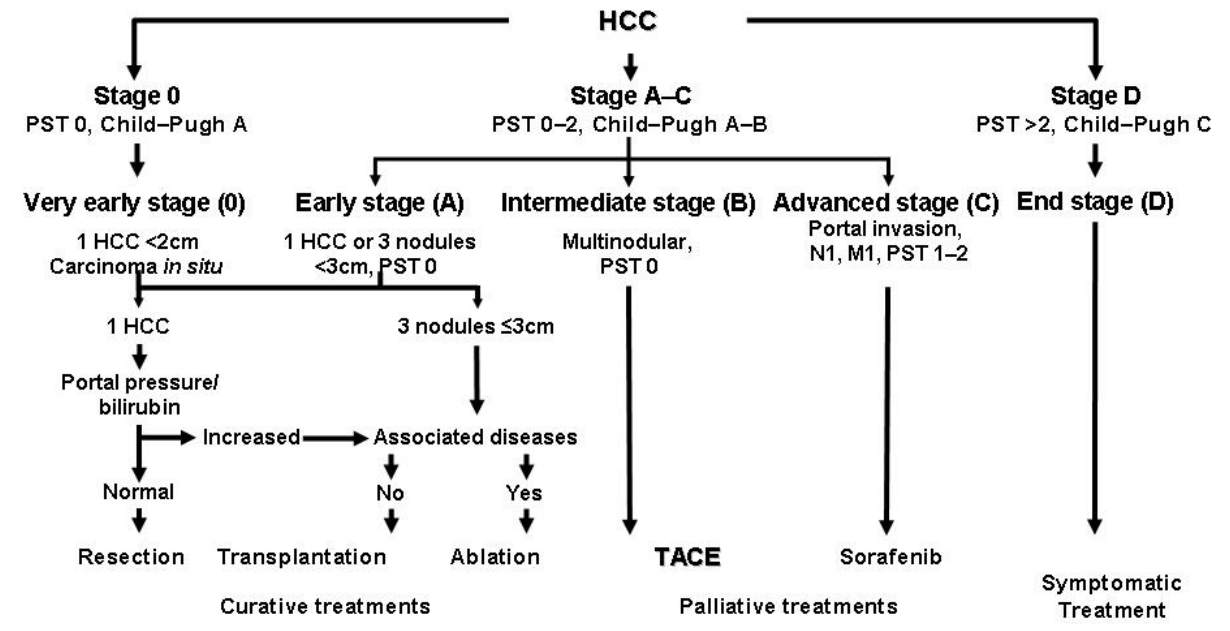

Adapted from Llovet JM et al. J Natl Cancer Inst 2008;100:698-711

Figure 1: BCLC staging and treatment strategy, 2008.

\section{Hypoxia in the post-TACE tumour micro-environment leads to angiogenesis}

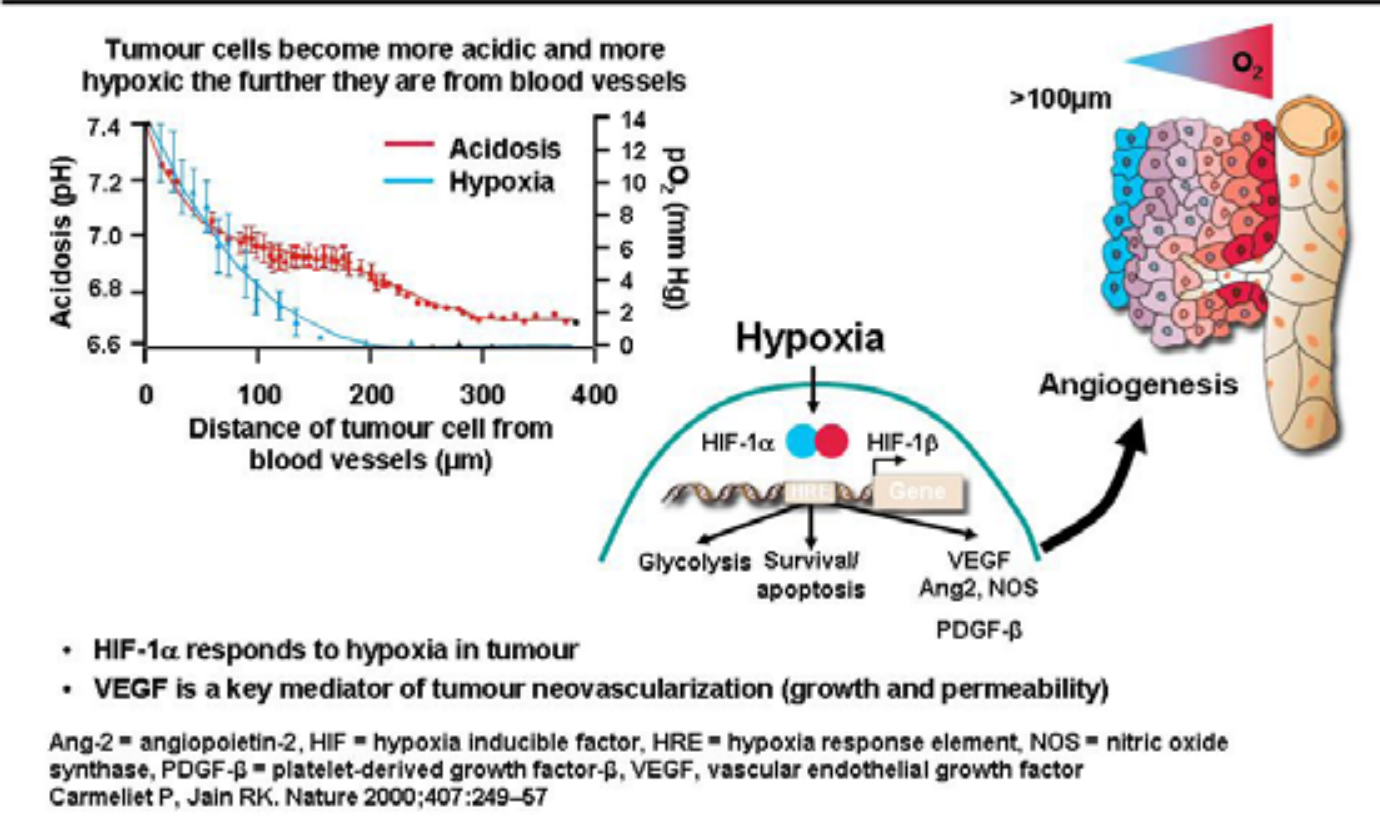

Figure 2: Hypoxia in the post-TACE tumour micro-environment leads to angiogenesis. 


\section{REFERENCES}

1. Llovet JM, Ricci S, Mazzaferro V, Hilgard P, Gane E, Blanc JF, et al. Sorafenib in advanced hepatocellular carcinoma. N.Engl.J.Med. 2008;359(4):378-90.

2. Llovet JM, Real MI, Montaña X, Planas R, Coll S, Aponte $\mathrm{J}$, et al. Arterial embolisation or chemoembolisation versus symptomatic treatment in patients with unresectable hepatocellular carcinoma: A randomised controlled trial. Lancet 2002;359(9319):1734-9.

3. Lo CM, Ngan H, Tso WK, Liu CL, Lam CM, Poon RTP, et al. Randomized controlled trial of transarterial Lipiodol chemoembolization for unresectable hepatocellular carcinoma. Hepatology 2002;35(5):1164-71.

4. Pelletier G, Ducreux M, Gay F, Luboinski M, Hagège H, Thong $\mathrm{D}$, et al. Treatment of unresectable hepatocellular carcinoma with lipiodol chemoembolization: A multicenter randomized trial. J.Hepatol. 1998;29(1):129-34.

5. Madden MV, Krige JEJ, Bailey S, Beningfield SJ, Geddes C, Werner ID, et al. Randomised trial of targeted chemotherapy with lipiodol and 5-epidoxorubicin compared with symptomatic treatment for hepatoma. Gut 1993;34(11):1598-600.

6. Trinchet JC, Rached AA, Beaugrand M, Mathieu D, Chevret S, Chastang C. A comparison of Lipiodol chemoembolization and conservative treatment for unresectable hepatocellular carcinoma. N.Engl.J.Med. 1995;332(19):1256-61.

7. Cammà $\mathrm{C}$, Schepis $\mathrm{F}$, Orlando $\mathrm{A}$, Albanese $\mathrm{M}$, Shahied $\mathrm{L}$, Trevisani $\mathrm{F}$, et al. Transarterial chemoembolization for unresectable hepatocellular carcinoma: Metaanalysis of randomized controlled trials. Radiology 2002; 224(1):47-54.

8. Simonetti RG, Liberati A, Angiolini C, Pagliaro L. Treatment of hepatocellular carcinoma: A systematic review of randomized controlled trials. Ann.Oncol. 1997;8(2):117-36

9. Mathurin P, Rixe O, Carbonell N, Bernard B, Cluzel P, Bellin MF, et al. Review article: Overview of medical treatments in unresectable hepatocellular carcinoma - an impossible meta-analysis? Alimen.Pharmacol.Therap. 1998;12(2):111-26.

10. Kulik LM, Carr BI, Mulcahy MF, Lewandowski RJ, Atassi B, Ryu RK, et al. Safety and efficacy of 90 Y radiotherapy for hepatocellular carcinoma with and without portal vein thrombosis. Hepatology 2008;47(1):71-81.

11. Salem R, Lewandowski RJ, Kulik L, Wang E, Riaz A, Ryu RK, et al. Radioembolization results in longer time-to-progression and reduced toxicity compared with chemoembolization in patients with hepatocellular carcinoma. Gastroenterology 2011;140(2):497-507.

12. Xiao EH, Guo D, Bian DJ. Effect of preoperative transcatheter arterial chemoembolization on angiogenesis of hepatocellular carcinoma cells. World J.Gastroenterol. 2009;15(36):4582-6.

13. Wang B, Xu H, Gao ZQ, Ning HF, Sun YQ, Cao GW. Increased expression of vascular endothelial growth factor in hepatocellular carcinoma after transcatheter arterial chemoembolization. Acta Radiol. 2008;49(5):523-9.
14. Okita K, Imanaka K, Chida N, et al. Phase III study of sorafenib in patients in Japan and Korea with advanced hepatocellular carcinoma (HCC) treated after transarterial chemoembolization (TACE). 2010 Gastrointestinal Cancers Symposium Orlando, FL; 2010; Abstr. LBA 128.

15. Li X, Feng GS, Zheng CS, Zhuo CK, Liu X. Influence of transarterial chemoembolization on angiogenesis and expression of vascular endothelial growth factor and basic fibroblast growth factor in rat with Walker-256 transplanted hepatoma: A experimental study. World J.Gastroenterol. 2003;9(11):2445-9.

16. Chemoembolization with or without sorafenib tosylate in treating patients with liver cancer that cannot be removed by surgery. 2010; Available at: http://clinicaltrials.gov./ ct2/show/NCT01004978?term $=$ NCT01004978\&rank $=1$.

17. Marelli L, Stigliano R, Triantos C, Senzolo M, Cholongitas $\mathrm{E}$, Davies N, et al. Transarterial therapy for hepatocellular carcinoma: Which technique is more effective? A systematic review of cohort and randomized studies. Cardiovasc.Intervent.Radiol. 2007;30(1):6-25.

18. Sinakos E, Dedes I, Papalavrentios L, Drevelegas A, Akriviadis E. Safety of transarterial chemoembolization plus sorafenib combination treatment in unresectable hepatocellular carcinoma. Scand.J.Gastroenterol. 2010;45(4):511-2.

19. Duan F, Wang MQ, Liu FY, Wang ZJ, Song P. Clinical observation of the treatment with combination of transcatheter arterial chemoembolization and sorafenib for hepatocellular carcinoma with lung metastasis. Zhonghua Zhong Liu Za Zhi 2009;31(9):716-8.

20. Cabrera R, George T, Soldevila Pico C, Firpi R, Morelli G and Nelson DR. Safety of sorafenib alone or in combination with locoregional therapy in patients with advanced hepatocellular carcinoma (HCC) and decompensated cirrhosis. 2008 ASCO Gastrointestinal Cancers Symposium Orlando, FL; 2008; Abstr. 147.

21. Martin RC, Keck G, Robbins K, et al. Evaluation of sorafenib in combination with doxorubicin-loaded DC bead as a combination treatment option for HCC. 2010 Gastrointestinal Cancers Symposium Orlando, FL; 2010; Abstr. 216.

22. Reyes DK, Azad NS, Koteish A, et al. Phase II trial of sorafenib combined with doxorubicin-eluting bead transarterial chemoembolization (DEB-TACE) for patients with unresectable hepatocellular carcinoma (HCC): Interim safety and efficacy analysis. 2010 Gastrointestinal Cancers Symposium Orlando, FL; 2010; Abstr. 254.

23. Chow PK, Poon D, Win KM, et al. Multicenter phase II study of SIR-sphere plus sorafenib as first-line treatment in patients with nonresectable hepatocellular carcinoma: The Asia-Pacific Hepatocellular Carcinoma Trials Group Protocol 05 (AHCC05). 2010 ASCO Annual Meeting Orlando, FL; 2010; Abstr. 4072.

24. Chung Y, Kim B, Chen C, et al. Study in Asia of the combination of transcatheter arterial chemoembolization (TACE) with sorafenib in patients with hepatocellular carcinoma (HCC) trial (START): Second interim safety and efficacy analysis. 2010 ASCO Annual Meeting Orlando, FL; 2010; Abstr. 4026. 